\title{
Highly selective anthraquinone-chalcone hybrids as potential antileukemia agents
}

\author{
Tatjana Stanojković a , Violeta Marković ${ }^{\mathrm{b}}$, Ivana Z. Matić ${ }^{\mathrm{a}}$, Milan P. Mladenovićb ${ }^{\mathrm{b}}$, Nina \\ Petrović $^{\text {a,c }}$, Ana Krivokuća ${ }^{a}$, Miloš Petković ${ }^{d}$, Milan D. Joksović ${ }^{\text {b,* }}$
}

\author{
${ }^{a}$ Institute of Oncology and Radiology of Serbia, Pasterova 14, 11000 Belgrade, Serbia \\ ${ }^{\mathrm{b}}$ Faculty of Science, Department of Chemistry, University of Kragujevac, R. Domanovica 12, 34000 \\ Kragujevac, Serbia \\ c Laboratory for Radiobiology and Molecular Genetics, "Vinča” Institute of Nuclear Sciences, 11000 Belgrade, \\ Serbia \\ ${ }^{d}$ Faculty of Pharmacy, Department of Organic Chemistry, University of Belgrade, Vojvode Stepe 450, 11221 \\ Belgrade, Serbia
}

\begin{abstract}
A series of 23 novel anthraquinone-chalcone hybrids containing amide function was synthesized and structurally characterized. Sixteen compounds exerted strong cytotoxic activities against K562, Jurkat and HL-60 leukemia cell lines and significantly lower cytotoxic effects against normal MRC-5 cells, indicating very high selectivity in their anticancer action. The compounds $\mathbf{6 g}, \mathbf{6 u}$ and $\mathbf{6 v}$ activate apoptosis in K562 cells through the extrinsic and intrinsic apoptotic pathway. The compound $\mathbf{6 e}$ triggered apoptosis in K562 cells only through the extrinsic apoptotic pathway. Treatment of K562 cells with each of these four compounds caused decrease in the expression levels of MMP2, MMP9, and VEGF, suggesting their anti-invasive, antimetastatic and antiangiogenic properties. The compounds $\mathbf{6 g}$ and $\mathbf{6 v}$ downregulated expression levels of miR-155 in K562 cells, while compounds 6e and 6u upregulated miR-155 levels in treated cells, in comparison with control cells. The structurebased 3-D QSAR models for $\mathbf{6 f}, \mathbf{6 e}, \mathbf{6} \mathbf{i}$ and $\mathbf{6} \mathbf{l}$ describe pro-apoptotic activity against caspase-3.
\end{abstract}

Keywords : anthraquinone-chalcone, leukemia, gene expression, miR-155, 3-D QSAR.

\footnotetext{
*Corresponding author. E-mail address: mjoksovic@kg.ac.rs (M.D. Joksović)
} 
Anticancer chalcones inhibit various molecular targets like ABCG2, 5 $\alpha$-reductase, histone deacetylases, p53 degradation, angiogenesis, tubulin and kinases. Human ABCG2, a member of ATP-binding cassette (ABC) transporters having a protecting role in cancer stem cells was inhibited by chalcones bearing quinoxaline unit [1]. Shimizu et al. isolated geranylated chalcones from Artocarpus incises for effective blocking intracellular $5 \alpha$ reductase to prevent proliferation of prostate cancer by arresting male androgen biosynthesis [2]. Coumarin-chalcone hybrids showed histone-deacetylase inhibitory activity when tested against leukemia K562 and U-937 cell lines [3]. Boronic-chalcones act as putative MDM2 antagonists interfering with p53-MDM2 interaction [4]. 4'-Hydroxy chalcone suppressed several steps of angiogenesis, including endothelial cell proliferation, migration and tube formation [5]. Matrix metalloproteinases-2/9, a family of enzymes that have ability to degrade many molecules of the extracellular matrix can be inhibited by prenylated chalcones containing hydroxyl groups on A or B ring [6]. 3,4,5-Trimethoxychalcones bind with microtubular protein tubulin and prevent its polymerization, which is essential phase for mitosis [7]. Chromenylchalcones successfully inhibit aurora kinase, a family of serine/threonine kinases, responsible for cell cycle control [8].

Anthraquinone is well known scaffold in anthracycline drugs such as daunorubicin, doxorubicin, mitoxantrone and ametantrone that are widely used for the treatment of cancer [9]. They act as intercalators [10], inhibitors of telomerase [11], DNA topoisomerase II [12] and ROS inducers in a redox cycle system by the presence of quinone intermediates [13]. The natural anthraquinone emodin induces apoptosis in human acute promyelocytic leukemia HL60 cells through activation of the caspase- 3 cascade, but independent of ROS production [14].

Although anthracyclines are effective against a wide variety of cancer cells, their clinical use is reduced due to low selectivity and high cardiotoxicity [9]. Incorporating anthraquinone ring in a chalcone system combined with an aromatic amide function, we tried to obtain hybrid molecules with synergistic or additive pharmacological properties. Thus, a series of new anthraquinone-chalcone hybrids having amide function were synthesized and screened for their anticancer and antidiabetic activity.

The synthesis of novel anthraquinone-chalcone hybrids containing amide function 6aw is presented in Scheme 1, while experimental details are provided in Supplementary material. The commercially available anthracene 1 was acylated using acetyl chloride to 1acetylanthracene 2 [15] which was then oxidized by chromium (VI) oxide in glacial acetic acid yielding 1-acetylanthraquinone 3 [16]. The ketone 3 was recrystallized from ethanol and condensed with 4-formylbenzoic acid in the presence of $\mathrm{NaOH}$ as a base catalyst, affording anthraquinone-chalcone carboxylic acid $\mathbf{4}$. The obtained intermediate $\mathbf{4}$ was then converted into acyl chloride using $\mathrm{SOCl}_{2}$, and, without isolation, reacted with selected primary amines in dry tetrahydrofuran giving the final hybrids 6a-w in moderate to good yields (51-88\%).

The structure of all compounds was confirmed by means of ${ }^{1} \mathrm{H}$ and ${ }^{13} \mathrm{C}$ NMR spectroscopy, IR and elemental analysis (see Supplementary material). The olefinic protons of the chalcone double bond in hybrid compounds $\mathbf{6 a - w}$, as well as their precursor 4, appeared as an $\mathrm{AB}$ system. On the basis of coupling constant values $(J=16.0-16.8 \mathrm{~Hz})$, all of the compounds were isolated and characterized in $E$-isomeric form. The signal for amide proton appears as a sharp singlet for compounds 6a-r at the highest ppm values (9.70-10.82 ppm), while for compounds $\mathbf{6 s - w}$ it exists as a triplet in slightly lower ppm range (8.53-9.20) due to the coupling with protons from adjacent methylene group. 


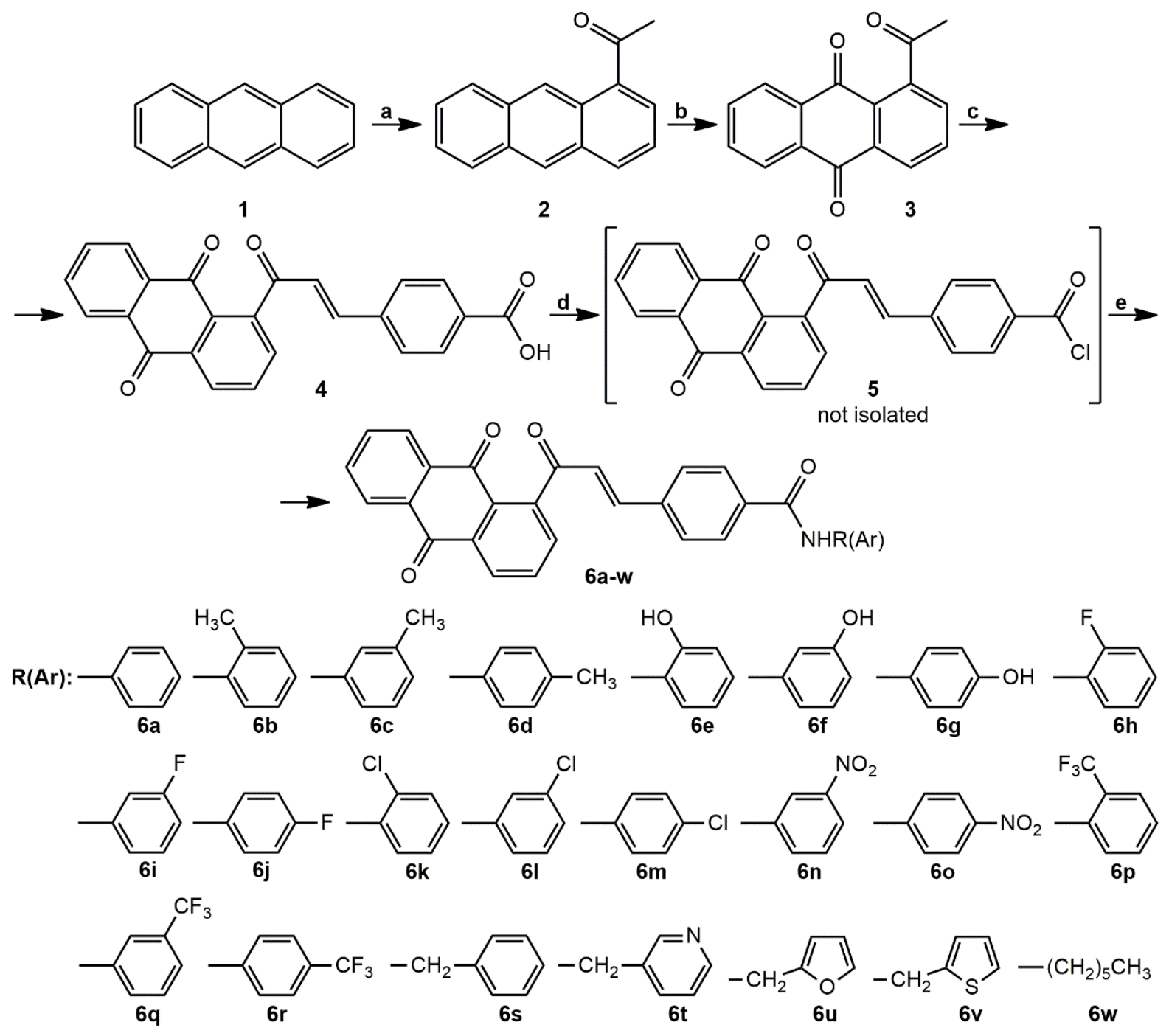

Scheme 1. Reagents and conditions: a) $\mathrm{CH}_{3} \mathrm{COCl}, \mathrm{AlCl}_{3}, \mathrm{CH}_{2} \mathrm{Cl}_{2}, 2 \mathrm{~h}, 0{ }^{\circ} \mathrm{C}, 5 \mathrm{M} \mathrm{HCl}$; b) $\mathrm{CrO}_{3}$, $\mathrm{CH}_{3} \mathrm{COOH}, 5$ min reflux, $\mathrm{H}_{2} \mathrm{O}$; c) 4-formylbenzoic acid, $\mathrm{NaOH}, \mathrm{MeOH}, 2 \mathrm{~h}$, reflux, $\mathrm{HCl}$; d) $\mathrm{SOCl}_{2}$, DMF, $\mathrm{CH}_{2} \mathrm{Cl}_{2}, 2 \mathrm{~h}$, rt; e) primary amine, THF, 6h, reflux, $\mathrm{H}_{2} \mathrm{O}$.

The cytotoxicity of anthraquinone-chalcone hybrids containing amide function $\mathbf{6 a - w}$ was evaluated against three human leukemia cancer cell lines (K562, Jurkat and HL-60), and normal human lung fibroblasts MRC-5 using MTT cell survival test. The obtained $\mathrm{IC}_{50}$ values are shown in Table 1.

Table 1. The cytotoxic activity of the investigated compounds $\mathbf{6 a - w}{ }^{a}$

\begin{tabular}{ccccc}
\hline & \multicolumn{4}{c}{ IC $50_{50} \pm \mathbf{S D}(\boldsymbol{\mu M})$} \\
\cline { 2 - 5 } Compd. & $\mathbf{K 5 6 2}$ & Jurkat & HL-60 & MRC-5 \\
\hline $\mathbf{6 a}$ & $10.93 \pm 1.70$ & $4.83 \pm 0.77$ & $6.81 \pm 1.16$ & $187.52 \pm 6.90$ \\
$\mathbf{6 b}$ & $29.01 \pm 1.64$ & $15.83 \pm 1.69$ & $17.53 \pm 2.04$ & $101.62 \pm 4.46$ \\
$\mathbf{6 c}$ & $25.03 \pm 1.87$ & $14.62 \pm 1.99$ & $17.56 \pm 0.36$ & $99.84 \pm 3.80$ \\
$\mathbf{6 d}$ & $5.39 \pm 0.59$ & $3.81 \pm 0.05$ & $7.06 \pm 1.03$ & $>200$ \\
$\mathbf{6 e}$ & $3.87 \pm 0.17$ & $3.23 \pm 0.04$ & $1.89 \pm 0.22$ & $60.36 \pm 4.17$ \\
$\mathbf{6 f}$ & $3.69 \pm 0.21$ & $3.22 \pm 0.14$ & $1.68 \pm 0.08$ & $17.07 \pm 3.01$
\end{tabular}




\begin{tabular}{ccccc}
$\mathbf{6 g}$ & $5.99 \pm 0.24$ & $3.66 \pm 0.41$ & $3.50 \pm 0.67$ & $190.74 \pm 7.73$ \\
$\mathbf{6 h}$ & $5.20 \pm 0.39$ & $4.22 \pm 0.51$ & $3.73 \pm 1.43$ & $126.84 \pm 20.52$ \\
$\mathbf{6 i}$ & $78.18 \pm 1.56$ & $27.64 \pm 3.27$ & $44.51 \pm 5.18$ & $191.12 \pm 2.23$ \\
$\mathbf{6 j}$ & $31.84 \pm 3.41$ & $28.14 \pm 2.39$ & $22.82 \pm 2.42$ & $>200$ \\
$\mathbf{6 k}$ & $4.67 \pm 0.35$ & $3.37 \pm 0.15$ & $4.22 \pm 0.70$ & $133.50 \pm 2.64$ \\
$\mathbf{6}$ & $95.11 \pm 6.92$ & $5.73 \pm 0.06$ & $36.66 \pm 2.81$ & $183.24 \pm 23.70$ \\
$\mathbf{6 m}$ & $8.53 \pm 0.41$ & $4.24 \pm 0.63$ & $5.71 \pm 0.15$ & $86.71 \pm 10.20$ \\
$\mathbf{6} \mathbf{n}$ & $23.14 \pm 2.19$ & $3.81 \pm 0.16$ & $4.06 \pm 1.59$ & $197.12 \pm 4.08$ \\
$\mathbf{6 o}$ & $25.52 \pm 0.90$ & $5.15 \pm 0.51$ & $3.57 \pm 1.25$ & $175.62 \pm 10.72$ \\
$\mathbf{6 p}$ & $5.24 \pm 0.92$ & $3.29 \pm 0.02$ & $3.55 \pm 0.69$ & $124.93 \pm 3.51$ \\
$\mathbf{6 q}$ & $7.14 \pm 0.66$ & $3.15 \pm 0.51$ & $2.81 \pm 1.13$ & $166.36 \pm 23.77$ \\
$\mathbf{6 r}$ & $12.84 \pm 1.03$ & $5.21 \pm 1.30$ & $4.24 \pm 0.69$ & $105.75 \pm 11.71$ \\
$\mathbf{6 s}$ & $3.96 \pm 0.95$ & $2.84 \pm 0.56$ & $3.85 \pm 0.75$ & $48.99 \pm 4.16$ \\
$\mathbf{6 t}$ & $4.40 \pm 0.41$ & $3.14 \pm 0.11$ & $2.40 \pm 0.69$ & $8.68 \pm 0.24$ \\
$\mathbf{6 u}$ & $4.45 \pm 0.73$ & $4.25 \pm 0.67$ & $3.16 \pm 1.12$ & $161.01 \pm 6.57$ \\
$\mathbf{6 v}$ & $4.35 \pm 0.47$ & $4.25 \pm 0.78$ & $4.43 \pm 0.78$ & $188.28 \pm 11.20$ \\
$\mathbf{6 w}$ & $5.08 \pm 0.66$ & $3.85 \pm 0.60$ & $5.39 \pm 0.85$ & $>200$ \\
$\mathbf{D O X}$ & $0.14 \pm 0.03$ & $0.11 \pm 0.03$ & $0.05 \pm 0.01$ & $0.29 \pm 0.05$ \\
\hline
\end{tabular}

${ }^{a}$ Results are mean values \pm SD of three independent experiments.

${ }^{\mathrm{b}}$ Doxorubicin.

Sixteen of the tested compounds showed excellent cytotoxic potential against all three cancer cell lines. As it can be seen from Table 1, there is no significant difference between the influence of electron-donating and electron-withdrawing groups of the aniline scaffold on the cytotoxic action against cancer cells. The derivatives $\mathbf{6 e}$ and $\mathbf{6} \mathbf{f}$ containing ortho- and meta-hydroxyphenyl group showed the best cytotoxic activity against K562 and HL-60 cell lines, with $\mathrm{IC}_{50}$ values of 3.87 and $3.69 \mu \mathrm{M}$ for K562 cells and 1.89 and $1.68 \mu \mathrm{M}$ for HL-60 cells, respectively. The compounds containing aromatic or heterocyclic ring linked to methylene group (6s-v), as well as derivative $\mathbf{6 w}$ containing alkyl group, also exerted potent antiproliferative activities against tested cell lines. The derivatives $\mathbf{6 i}$ and $\mathbf{6 1}$ containing electron-withdrawing groups ( $\mathrm{F}$ and $\mathrm{Cl}$, respectively) at meta-position of the aniline moiety, showed significantly lower activity against K562 cell line, compared to other tested compounds.

All tested compounds, except $\mathbf{6} \mathbf{f}$ and $\mathbf{6 t}$, showed significantly lower toxicity towards normal MRC-5 cells, compared to our previously presented anthraquinone derivatives containing two chalcone moieties [17], and especially in comparison with anthraquinone based chalcone analogues containing imine fragment [18]. Moreover, all tested derivatives showed lower toxicity against normal MRC-5 cells comparing to cisplatin as a referent drug. The selectivity index (SI $=\mathrm{IC}_{50}(\mathrm{MRC}-5) / \mathrm{IC}_{50}$ (cancer cells)) of a number of the tested compounds was found to be over 50.0, with compound $\mathbf{6 q}$, containing metatrifluoromethylphenyl group, showing the highest SI of 59.2 in case of HL-60 cells. In light of these facts, compounds $\mathbf{6 e}, \mathbf{6 g}, \mathbf{6 u}$ and $\mathbf{6 v}$ were selected for all further analyses due to their prominent cytotoxic activity and excellent selectivity in the antiproliferative action against K562 cell line.

Apoptosis is one of the main types of programmed cell death, and many anticancer agents induce apoptosis as a result of their cytotoxic action [19]. To test the ability of the investigated compounds $\mathbf{6 e}, \mathbf{6 g}, \mathbf{6} \mathbf{u}$, and $\mathbf{6 v}$ to induce cell death, the cell cycle analysis was performed. The distribution of the cell cycle was investigated on K562 cells, which were 
selected because of a somewhat weaker sensitivity to the tested compounds in comparison with other two lines of malignant cells. For the compounds $6 \mathbf{6 e}, \mathbf{6 g}, \mathbf{6 u}$, and $\mathbf{6 v}$, the changes in cell cycle phase distribution of $\mathrm{K} 562$ cells treated with $\mathrm{IC}_{50}$ and $2 \mathrm{IC}_{50}$ concentrations after 24 $\mathrm{h}$ were assessed. The effects of the selected compounds on cell cycle distribution of K562 myelogenous leukemia cells are shown in Fig.1.

A

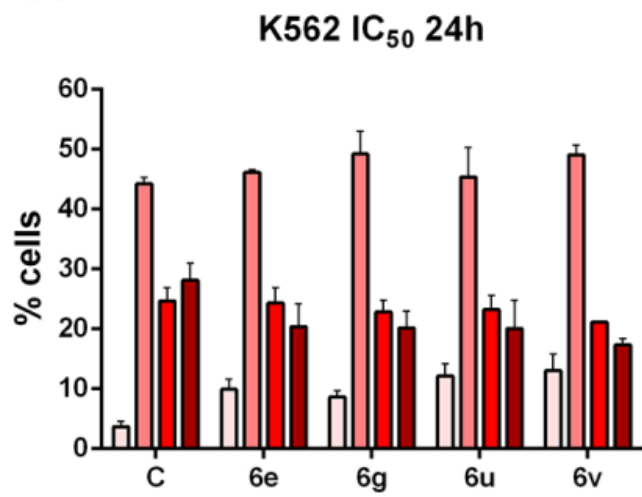

B

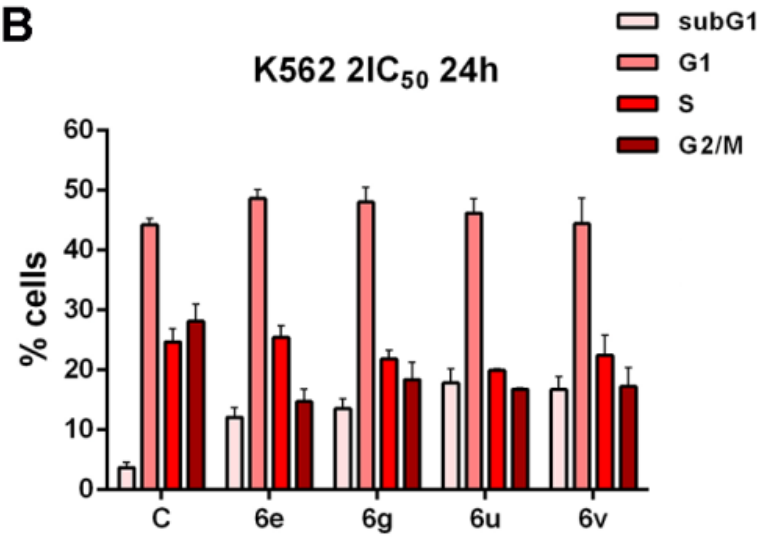

Fig. 1. Changes in the cell cycle phase distribution of $\mathrm{K} 562$ cells treated with $\mathrm{IC}_{50}(\mathrm{~A})$ and $2 \mathrm{IC}_{50}$ concentrations (B) of the compounds $6 \mathbf{e}, \mathbf{6 g}, \mathbf{6} \mathbf{u}$ and $\mathbf{6 v}$ for $24 \mathrm{~h}$.

The subG1 population represents dead cells containing only fractional DNA content. Our results showed an increase in the DNA fragmentation in K562 cells in a dose-dependent manner after treatment with given compounds, as reflected by the increase in the percentages of cells in the subG1 phase. This treatment caused a concomitant decrease in the proportion of cells in $\mathrm{G} 2 / \mathrm{M}$ phase of the cell cycle compared to the control cells. Thus, treatment of the K562 cells with the compounds $\mathbf{6 e}, \mathbf{6 g}, \mathbf{6 u}$, and $\mathbf{6 v}$ resulted in a pronounced accumulation of cells in the subG1 phase of the cell cycle, pointing out an ability of the examined compounds to induce cell death in chronic myelogenous leukemia cells.

To get an insight into possible mechanisms of cell death type triggered by the compounds $6 \mathbf{e}, \mathbf{6 g}, \mathbf{6 u}$ and $\mathbf{6 v}$, we explored their ability to induce apoptosis in K562 cells in presence of specific inhibitors of caspase-3, caspase- 8 and caspase- 9 . As it could be seen in Fig 2, the decrease in the percentage of cells in subG1 cell cycle phase was found in K562 cell samples which were pretreated with Z-DEVD-FMK, an inhibitor of caspase-3 and afterwards exposed to compounds $\mathbf{6 e}, \mathbf{6 g}, \mathbf{6 u}$ and $\mathbf{6 v}$. The comparison was made with K562 cell samples which were not pretreated with inhibitor before addition of the selected compound. These results point out the pro-apoptotic activity of all the tested compounds. Pretreatment of K562 cells with Z-IETD-FMK, inhibitor of caspase-8 and a treatment with each of the four compounds induced remarkable decrease in the percentage of subG1 cells in comparison with cell samples which were only incubated with these compounds, indicating the ability of our compounds to activate apoptosis in K562 cells through extrinsic apoptotic signaling pathway via death receptors. In addition, lower percentage of K562 cells within subG1 phase was observed in the cell samples pretreated with Z-LEHD-FMK, an inhibitor of caspase-9 and treated with compounds $\mathbf{6 g}, \mathbf{6 u}$ and $\mathbf{6 v}$ when compared with those percentages in cell samples which were not pretreated with the inhibitor. Pretreatment with caspase-9 inhibitor did not cause changes in the percentage of cells in subG1 phase incubated with the compound $\mathbf{6 e}$. Our results demonstrate that compounds $\mathbf{6 g}, \mathbf{6 u}$ and $\mathbf{6 v}$ also activate intrinsic or mitochondrial apoptotic signaling pathway. 

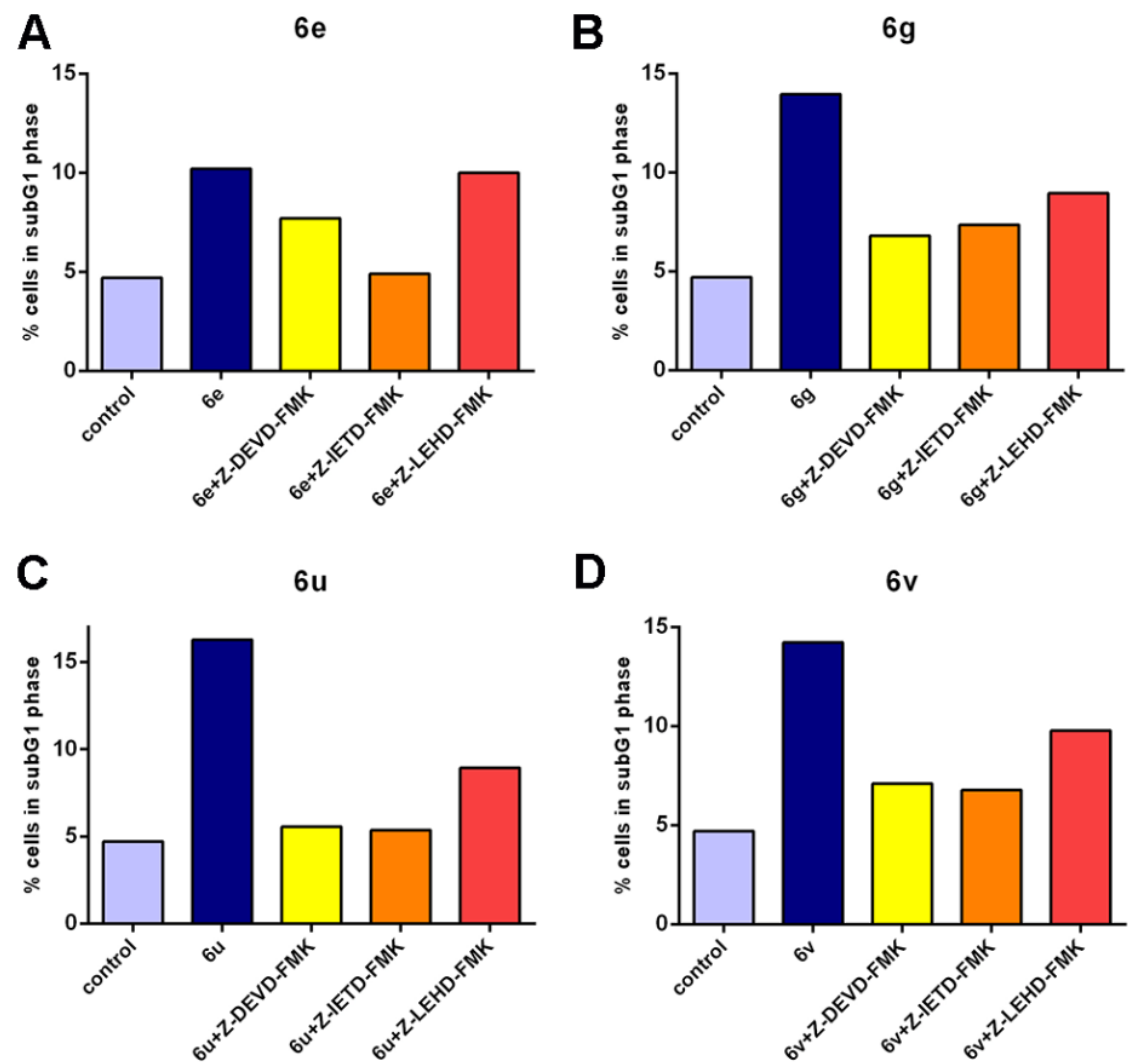

Fig. 2. Effects of the specific caspase inhibitors (Z-DEVD-FMK - caspase-3 inhibitor, Z-IETD-FMK -caspase-8 inhibitor, Z-LEHD-FMK - caspase-9 inhibitor) on the percentages of K562 cells within subG1 phase treated with $2 \mathrm{IC}_{50}$ concentrations of the compounds $6 \mathbf{e}(\mathrm{A}), \mathbf{6 g}(\mathrm{B}), \mathbf{6 u}(\mathrm{C})$, and $\mathbf{6 v}(\mathrm{D})$.

The cell migration and angiogenesis in myeloid leukemia (ML) cells are accompanied by an increased expression of MMP2, MMP9, VEGFA and miR-155. MiR-155 was first proposed to be oncogenic but later, miR-155 has also been reported to be downregulated in various haematological malignancies suggesting its different roles depending on the type of malignancy and its ability to inhibit many target genes [20,21]. The K562 cells treated with compounds $6 \mathrm{~g}$ and $\mathbf{6 v}$ had lower levels of miR-155 compared with control cells, while the cells treated with compounds $\mathbf{6 e}$ and $\mathbf{6 u}$ showed higher levels of miR-155 compared with the control cells (Fig. 3). The K562 cells treated with 6e showed the highest level of miR-155 expression and the lowest expression level of miR-155 was detected for 6g. Evidently, the different position of the same hydroxyl group attached to aromatic ring of $6 \mathbf{e}$ and $\mathbf{6 g}$ made a great difference in miR-155 expression. The targeting miR-155 with anti-miR-155 resulted in a significant decrease of miR-155 expression compared to negative control in the human acute promyelocytic leukemia HL-60 cells, downregulated Slug and upregulated PUMA expression, decreased HL-60 cell growth and increased HL-60 cell apoptosis [22]. On the other hand, the overexpression of miR-155 together with myeloid maturation was found to induce apoptosis in HL-60 cells through caspase-3 activation [23]. Although miR-155 has been postulated as oncogenic in various types of cancer including hematological malignancies, it was reported to be downregulated in chronic myelogenous leukemia K562 cells $[24,25]$. The downregulation of miR-155 could be attributed to BCR-ABL tyrosine kinase activity [25]. It was showed that overexpression of miR-155 in K562 cells caused upregulation of p27kip1 and induction of apoptosis [24]. Our results showed induction of 
apoptosis upon miR-155 overexpression in K562 cells treated with compounds $6 \mathbf{e}$ and $\mathbf{6 u}$. This behavior might be attributed to high complexity of miRNA target selection and regulation in different types of leukemia cells [24]. Furthermore, miR-155 might target both oncogene and tumor suppressors to varying degrees within the same cells, as it was demonstrated for miR-196b [26] and finally, miR-155 may exhibit different function depending on its expression level [27].

All K562 cell samples treated with examined anthraquinone-chalcones $6 \mathbf{e}, \mathbf{6 g}, \mathbf{6 u}$ and 6v showed reduced levels of $M M P 2, M M P 9$, and VEGFA. Angiogenesis is an important step in the development and progression of various types of malignancies, including leukemia. VEGFA plays a crucial role in regulation of angiogenesis via binding to the vascular endothelial growth factor receptor 2 (VEGFR2), which leads to the activation of downstream VEGF signaling cascade, resulting in in vitro cell proliferation, migration, and angiogenesis [28]. It has been shown that activation of VEGF downstream signaling induces angiogenesis in ML cells [29]. Additionally, upregulation of VEGFA promotes ML cell proliferation, survival and resistance to chemotherapy [30]. Furthermore, it has been shown that several anthraquinone derivatives including Emodin have inhibitory effect on tumor angiogenesis, through silencing VEGFA signaling cascade in leukemic cell line models [31, 32]. Our study showed that K562 cells treated with anthraquinone-chalcone hybrids $\mathbf{6 e}, \mathbf{6 g}, \mathbf{6 u}$ and $\mathbf{6 v}$ had noticeable reduced expression levels of $V E G F A$, indicating their potential antiangiogenic properties.

The MMP2 and MMP9 overexpression in leukemia is associated with crossing of leukemic cell blasts into the blood and can promote invasion and metastasis into distant organs [33]. Furthermore, all K562 cell samples treated with $\mathbf{6 e}, \mathbf{6 g}$, 6u and 6v showed decreased levels of $M M P 2$ and $M M P 9$ indicating their potential anti-invasive and antimetastatic properties. The simultaneous effect of examined anthraquinone-chalcone hybrids on decrease of VEGF, MMP2 and MMP9 expression in K562 cells compared with control, untreated cells might have a promising effect in future therapies for ML. These results might indicate that future therapeutics in the treatment of ML may be focused on antiangiogenic therapy [34], and on the introduction of additional anticancer agents such as anthraquinone-chalcone conjugates in combination with standard therapeutics. 
A

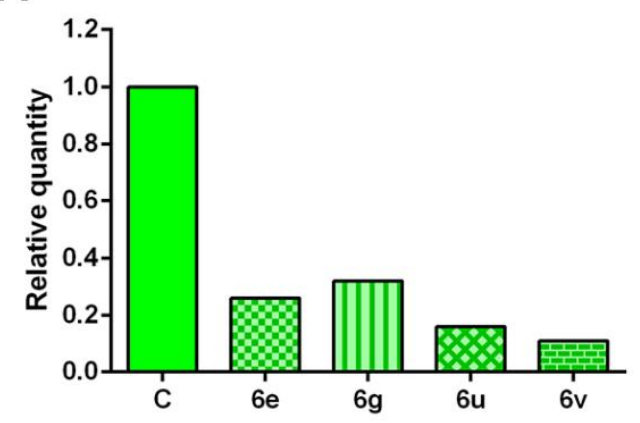

C

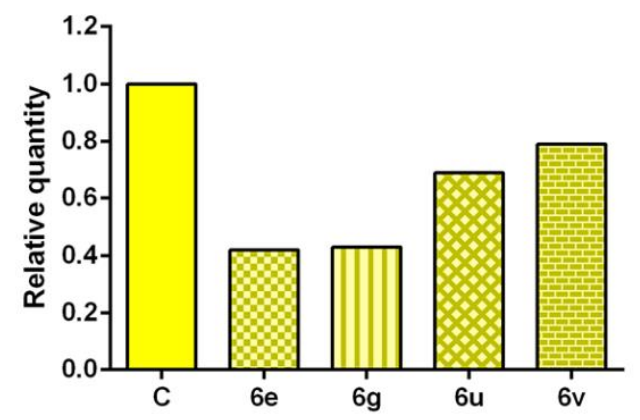

B

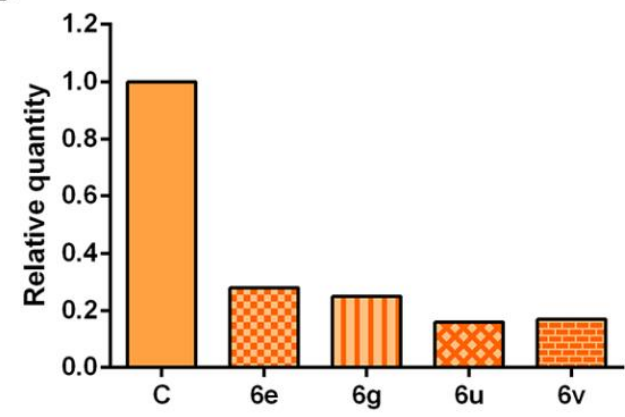

D

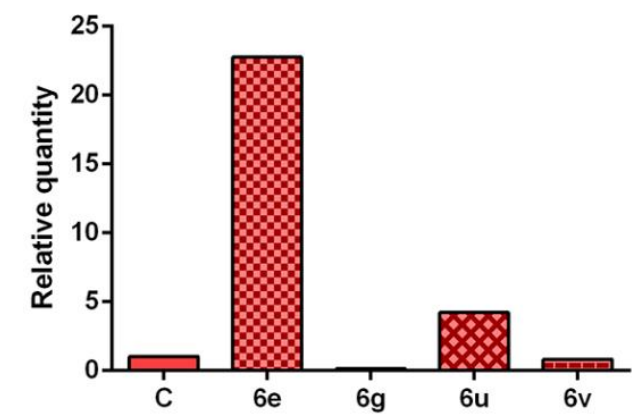

Fig. 3. Changes in expression levels of $M M P 2$ gene (A), $M M P 9$ gene (B), VEGFA gene (C), and miR155 in $\mathrm{K} 562$ cells exposed to subtoxic $\mathrm{IC}_{20}$ concentrations of the compounds $6 \mathbf{e}(1.5 \mu \mathrm{M}), 6 \mathbf{g}(2 \mu \mathrm{M})$, $\mathbf{6 u}(1.5 \mu \mathrm{M})$ and $\mathbf{6 v}(1.5 \mu \mathrm{M})$ for $24 \mathrm{~h}$.

Herein results, considering the miR-155 expression, imply that the elaborated compounds act as pro-apoptotic agents at signal transduction extrinsic pathway level in the form of caspase-3 efectors [35]. To the best of our knowledge, there are no deposited crystallographic data at Protein Data Bank, concerning the co-crystallized 6a-w-caspase-3 complexes. Therefore, compounds' 6a-w bioactive conformations were precluded by means of molecular docking, by exploring their binding modes in caspase-3 co-crystallized with isoquinoline-1,3,4-trione derivatives (PDB code: 3DEI) [36], utilizing the search algorithms and scoring functions as implemented in AutoDock Vina [37]. Following, the biophysical rationale leading to the compounds' $6 \mathbf{a}-\mathbf{w}$ pro-apoptotic activity was revealed by virtue of generating the structure-based 3-D QSAR models, as instructed in Open3DQSAR methodology [38]. The bi-probe 3-D QSAR model (Supplementary Tables S1 and S2), derived from carbonyl oxygen as hydrogen bond (HB) acceptor (i.e. the O]C probe form MMFF94 force filed) and electrostatic charge (i.e. the ELE filed), explained compounds' 6aw biopotential by cause of steric/HB and electrostatic interactions (Fig. 4, Supplementary material Figs. S49A and S49C). The molecular docking and 3-D QSAR studies external validation were performed on a set of anthraquinones from Morinda citrifolia, as leukaemia cell line K562 inhibitors (Supplementary material Figs. S49B and S49D) [39]. Molecular docking and 3-D QSAR experimented details are provided in Supplementary material. 


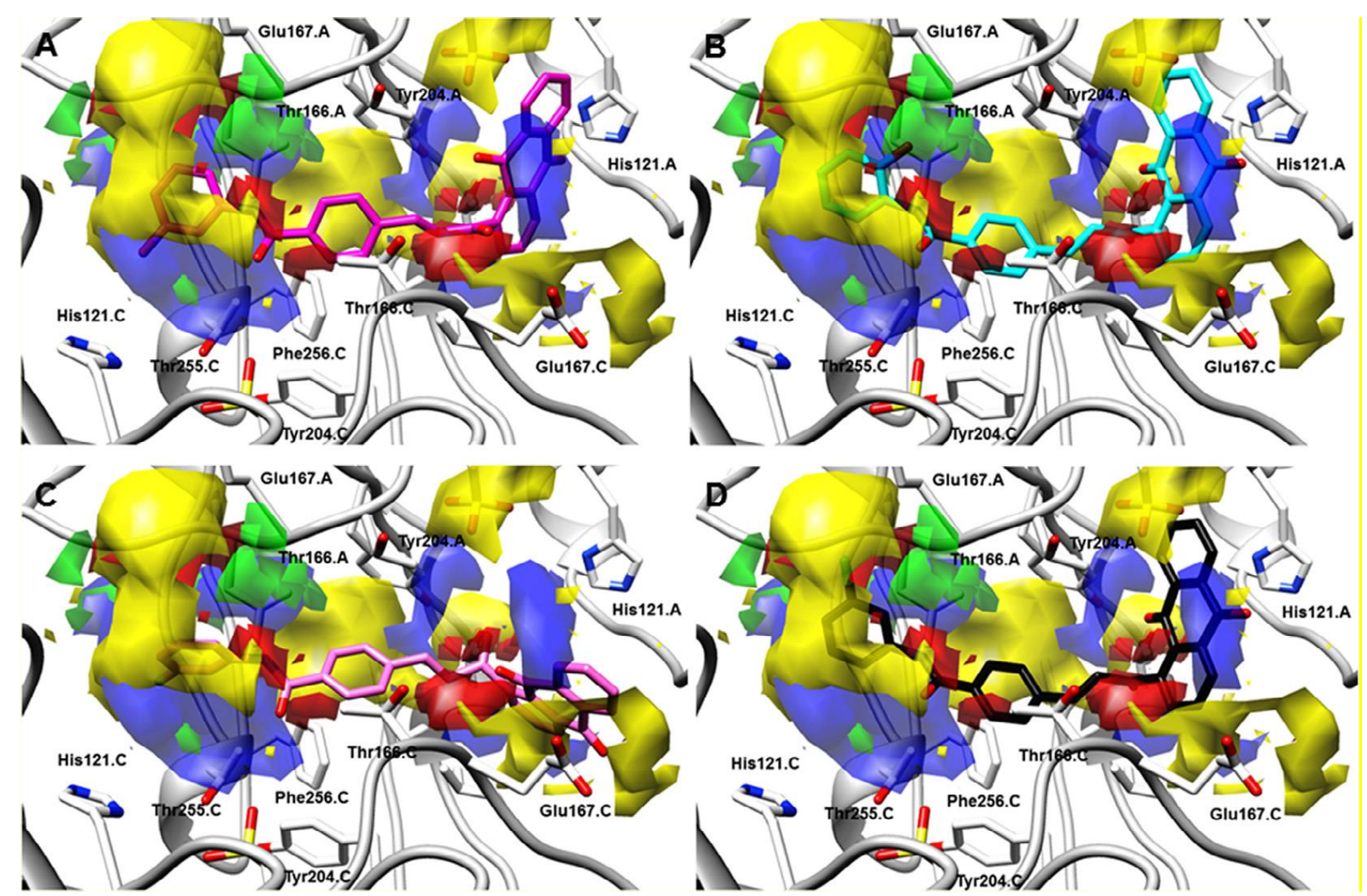

Fig. 4. Structure-based 3-D QSAR models for $6 \mathbf{f}(\mathrm{A}), \mathbf{6 e}(\mathrm{B}), \mathbf{6 i}(\mathrm{C}), \mathbf{6 l}$ (D) describing proapoptotic activity against caspase-3. Caspase-3 is depicted in white. Positive $\mathrm{O}=\mathrm{C}_{\text {PLS-coefficients }}$ are illustrated in green, negative $\mathrm{O}=\mathrm{C}_{\text {PLS-coefficients }}$ are drawn in yellow, positive ELEPLScoefficients are colored in red, negative ELEPLS-coefficients are presented in blue.

The compounds' 6a-w bioactive conformations are established at chain A-chain $\mathrm{C}$ dimer interface, within the capase-3 tetramer structure, inside the hydrophobic pocket compiled of Thr166, Leu168, Tyr204, Trp206, Thr255, and Phe256, at the edge of the active site. As the most active pro-apoptotic agent, derivative 6f (Fig. 4A) forms several strong hydrophobic interactions with the unsubstituted aromatic part of anthraquinone core: with the side chain methyl group of Thr166 from chain A (further on Thr166.A or similar abbreviation), with Tyr204.A, and with the side chain methyl group of Thr255.A. Particular attractions are verified by the appearance of negative 3-D QSAR $\mathrm{O}=\mathrm{C}_{\text {PLScoefficients }}$ (yellow maps, indicators of repulsive hydrophobic interactions). Similar interactions were a characteristic of the second ranked compound, 6e (Fig. 4B), as well. Other important steric clash, also confirmed by negative $\mathrm{O}=\mathrm{C}_{\text {PLS-coefficients, }}$ is formed between the substituted aromatic moiety of the anthraquinone core and the side chain of Glu167.A. Comparable alignment of the anthracene9,10 -dione core is seen for the remaining compounds, too. The slight drop in the potency of $\mathbf{6 e}$, related to $\mathbf{6 f}$, can be initially attributed to the $\mathbf{6 e}$ anthraquinone core rotation in comparison to 6f, where rings are orthogonal to each other. Carbonyl groups within the anthracene-9,10-dione give significant contribution to the activity: the C9 carbonyl oxygen is, according to the alignment of negative ELEPLS-coefficients (blue maps) involved in electrostatic interactions with Thr166.A and Thr166.C.

Moreover, with the progress in anthraquinone-chalcone hybrid structures, the chalcone phenyl ring, common to all compounds, is attracted by Phe142.A or Leu168.A (negative $\mathrm{O}=\mathrm{C}_{\text {PLS-coefficients }}$ as proof). Precise attraction is facilitated by the antraquinone-chalcone carbonyl linker, a function that is within the bioactive conformation of $\mathbf{6} \mathbf{f}$ oriented towards the hydroxyl group of Thr166.C, whereas for 6e is directed to Thr255.A. Each of the interactions is described by positive ELEPLS-coefficients (red maps), implying electron- 
withdrawing potential of carbonyl linker as important for the activity. With over $5 \AA$ in distance between the electron-withdrawing center and Thr255.A(C)-OH group as potential HB donor, the possibility of hydrogen bonding is excluded.

The true difference in the activity of evaluated derivatives lies in the contribution of $\mathrm{R}(\mathrm{Ar})$ substituents. They are introduced into thecaspase- 3 active site via the amide carbonyl linker between the chalcone aromatic scaffold and the $\mathrm{R}(\mathrm{Ar})$ substituents. The distinct linker contributes to the pro-apoptotic potency by making electrostatic interactions with Thr255.A and Tyr204.C, respectively. Consequently, phenolic aromates of $\mathbf{6} \mathbf{f}$ and $\mathbf{6 e}$ are involved in the weak steric hindrance with His 121.C (as verified by the superposition of negative $\mathrm{O}=\mathrm{C}_{\mathrm{PLS}}$ coefficients maps as attractive interactions indicators). According the alignment of negative ELEPLS-coefficients (blue maps), the meta-hydroxyphenyl function of $\mathbf{6} \mathbf{f}$ is engaged in hydrogen bonding with Thr255.A $\left(\mathrm{d}_{\mathrm{HB}}=2.314 \AA\right)$, indicating that the particular hydroxyl group serves as an HB acceptor to the active site residue. On the other hand, the ortho-hydroxyphenyl function of $\mathbf{6 e}$ is facing Thr166.A to create only electrostatic attraction (negative ELEPLScoefficients as proof), and, consequently, the activity of $\mathbf{6 e}$ is diminished. The establishment of hydrogen bond/electrostatic interactions with Thr166.A/Thr255.A is of the highest importance for the pro-apoptotic activity, inasmuch as the substitution of - $\mathrm{OH}$ group with other electron-withdrawing groups (like halogens, 6i, and 6l, Figs. 4C and D, respectively), alleviates the activity in significant manner.

In conclusion, we have synthesized a series of twenty-three amide derivatives combining anthraquinone-chalcone carboxylic acid and corresponding primary amines. Four examined anthraquinone-chalcone hybrids exerted strong cytotoxic activity against different human leukemia cell lines with remarkably lower toxicity against normal MRC-5 cells. The compounds showed the ability to trigger apoptotic cell death in K562 cells through activation of extrinsic and intrinsic signaling pathway, with the exception of compound $\mathbf{6 e}$ which activated only extrinsic pathway. Treatment of K562 cells with each of the four selected compounds decreased the expression levels of $M M P 2, M M P 9$ and VEGFA genes, indicating their anti-angiogenic, anti-invasive and antimetastatic activities. MiR-155 expression strongly depends on the nature and position of substituents attached to aromatic ring. Heteroaromatics, furan and thiophene also cause great difference of miR-155 expression in K562 cells. As the most active pro-apoptotic agents, derivatives $6 \mathbf{f}$ and $\mathbf{6 e}$ form several strong hydrophobic interactions with the unsubstituted aromatic part of anthraquinone core. In conclusion, our research may suggest promising antileukemic potential of newly synthesized anthraquinonechalcone hybrids.

\section{Acknowledgments}

The authors are grateful to the Ministry of Science and Technological Development of the Republic of Serbia for financial support (Grant Nos 172016 and 175011).

\section{Appendix A. Supplementary data}

Supplementary data (experimental procedures, spectral data, copies of $1 \mathrm{H}$ and 13C NMR spectra) associated with this article can be found, in the online version, at http://dx.doi.org/10.1016/j.bmcl.2018.06.048.

\section{References}


1. E. Winter, G.J. Gozzi, L.D. Chiaradia-Delatorre, N. Daflon-Yunes, R. Terreux,C. Gauthier, A. Mascarello, P.C. Leal, S.M. Cadena, R.A. Yunes, R.J. Nunes, T.B. Creczynski-Pasa, A.D. Pietro, Quinoxaline-substituted chalcones as new inhibitors of breast cancer resistance protein ABCG2: polyspecificity at B-ringposition, Drug Des. Dev. Ther. 8 (2014) 609-619.

2. K. Shimizu, R. Kondo, K. Sakai, S. Buabarn, U. Dilokkunanant, A geranylated chalcone with $5 \alpha-$ reductase inhibitory properties from Artocarpus incises, Phytochemistry 54 (2000) 737-739.

3. C. Seidel, M. Schnekenburger, C. Zwergel, F. Gaascht, A. Mai, M. Dicato, G. Kirsch, S. Valente, M. Diederich, Novel inhibitors of human histone deacetylases: design, synthesis and bioactivity of 3alkenoylcoumarines, Bioorg. Med. Chem. Lett. 24 (16) (2014) 3797-3801.

4. S.K. Kumar, E. Hager, C. Pettit, H. Gurulingappa, N.E. Davidson, S.R. Khan, Design, synthesis, and evaluation of novel boronic-chalcone derivatives as antitumor agents, J. Med. Chem. 46 (2003) 2813-2815.

5. L. Varinska, M. Wijhe, M. Belleri, S. Mitola, P. Perjesi, M. Presta, P. Koolwijk, L. Ivanova, J. Mojzis, Anti-angiogenic activity of the flavonoid precursor 4-hydroxychalcone, Eur. J. Pharmacol. 691 (2012) $125-133$.

6. B. Ngameni, M. Touaibia, R. Patnam, A. Belkaid, P. Sonna, B.T. Ngadjui, B. Annabi, R. Roy, Inhibition of MMP-2 secretion from brain tumor cells suggests chemopreventive properties of a furanocoumarin glycoside and of chalcones isolated from the twigs of Dorstenia turbinate, Phytochemistry 67 (2006) 2573-2579.

7. L.B. Salum, W.F. Altei, L.D. Chiaradia, M.N.S. Cordeiro, R.R. Canevarolo, C.P.S. Melo, E. Winter, B. Mattei, H.N. Daghestani, M.C. Santos-Silva, T.B. Creczynski-Pasa, R.A. Yunes, J.A. Yunes, A.D. Andricopulo, B.W. Day, R.J. Nunes, A. Vogt, Cytotoxic 3, 4, 5-trimethoxychalcones as mitotic arresters and cell migration inhibitors, Eur. J. Med. Chem. 63 (2013) 501-510.

8. S.Y. Shin, H. Yoon, S. Ahn, D. Kim, Sang Ho Kim, Dongsoo Koh, Young Han Lee, Yoongho Lim, Chromenylchalcones showing cytotoxicity on human colon cancer cell lines and in silico docking with aurora kinases, Bioorg. Med. Chem. 21 (2013) 4250-4258.

9. J.W. Lown, Anthracycline and Anthracenedione-based Anticancer Agents, Elsevier, Amsterdam, 1988.

10. M. Agbandje, T.C. Jenkins, R. McKenna, A.P. Reszka, S. Neidle, Anthracene-9,10-diones as potential anticancer agents. Synthesis, DNA-binding, and biological studies on a series of 2,6-disubstituted derivatives, J. Med. Chem. 35 (1992) 1418-1429.

11. G. Zagotto, C. Sissi, L. Lucatello, C. Pivetta, S.A. Cadamuro, K.R. Fox, S. Neidle, M. Palumbo, Aminoacyl-anthraquinone conjugates as telomerase inhibitors: synthesis, biophysical and biological evaluation, J. Med. Chem. 51 (2008) 5566-5574.

12. H. Suzuki, T. Ikeda, T. Yamagishi, S. Nakaike, S. Nakane, M. Ohsawa, Efficient induction of chromosome-type aberrations by topoisomerase II inhibitors closely associated with stabilization of the cleavable complex in cultured fibroblastic cells, Mutat. Res. 328 (1995) 151-161.

13. G. Powis, Free radical formation by antitumor quinones, Free Radic. Biol. Med. 6 (1989) 63-101.

14. Y.-C. Chen, S.-C. Shen, W.-R. Lee, F.-L. Hsu, H.-Y. Lin, C.-H. Ko, S.-W. Tseng, Emodin induces apoptosis in human promyeloleukemic HL-60 cells accompanied by activation of caspase-3 cascade but independent of reactive oxygen species production, Biochem. Pharmacol. 64 (2002) 1713-1724.

15. M. Stolka, J.F. Yanus, J.M. Pearson, Polymerization of vinylanthracene monomers. 3. 1- and 9vinylanthracenes, Macromolecules 9 (1976) 715-719.

16. H.F. Bassilios, M. Shawky, A.Y. Salem, Acetylation of anthracene by the Friedel-Crafts reaction, using ethylene chloride as the solvent, Recl. Trav. Chim. Pays-Bas 82 (1963) 298-301.

17. V. Marković, N. Debeljak, T. Stanojković, B. Kolundžija, D. Sladić, M. Vujčić, B. Janović, N. Tanić, M. Perović, V. Tešić, J. Antić, M. D. Joksović, Anthraquinone-chalcone hybrids: Synthesis, preliminary antiproliferative evaluation and DNA-interaction studies, Eur. J. Med. Chem. 89 (2015) 401-410.

18. B. Kolundžija, V. Marković, T. Stanojković, Lj. Joksović, I. Matić, N. Todorović, M. Nikolić, M. D. Joksović, Novel anthraquinone based chalcone analogues containing an imine fragment: Synthesis, cytotoxicity and anti-angiogenic activity, Bioorg. Med. Chem. Lett. 24(1) (2014) 65-71.

19. S. Elmore, Apoptosis: A Review of Programmed Cell Death Toxicol. Pathol. 35 (2007) 495-516.

20. I. Faraoni, S. Laterza, D. Ardiri, C. Ciardi, F. Fazi, F. Lo-Coco, MiR-424 and miR-155 deregulated expression in cytogenetically normal acute myeloid leukaemia: correlation with NPM1 and FLT3 mutation status, J. Hematol. Oncol. 5 (2012) 26.

21. M. Jongen-Lavrencic, S.M. Sun, M.K. Dijkstra, P.J.M. Valk, B. Löwenberg, MicroRNA expression profiling in relation to the genetic heterogeneity of acute myeloid leukemia, Blood 111 (2008) 5078-5085. 
22. H. Liang, Z. Dong, J.-F. Liu, W. Chuang, L.-Z. Gao, Y.-G. Ren, Targeting miR-155 suppresses proliferation and induces apoptosis of HL-60 cells by targeting Slug/PUMA signal, Histol. Histopathol. 32 (2017) 899-907.

23. C.A. Palma, D.A. Sheikha, T.K. Lim, A. Bryant, T.T. Vu, V. Jayaswal, D.D.F. Ma, MicroRNA-155 as an inducer of apoptosis and cell differentiation in Acute Myeloid Leukaemia, Mol. Cancer 13 (2014) 79.

24. O.H. Rokah, G. Granot, A. Ovcharenko, S. Modai, M. Pasmanik-Chor, A. Toren, N. Shomron, O. Shpilberg, Downregulation of miR-31, miR-155, and miR-564 in chronic myeloid leukemia cells, PLoS One 7 (2012) e35501.

25. M. Edalati Fathabad, M. Karimipoor, S. Alizadeh, A. Abdoli, A. Atashi, M. Sayadi M, miR-155 effectively induces apoptosis in K562 Philadelphia positive cell line through upregulation of p27kip1, Bioimpacts 7(2017) 109-114.

26. Z. Li, H. Huang, P. Chen, M. He, Y. Li, S. Arnovitz, X. Jiang, C. He, E. Hyjek, J. Zhang, Z. Zhang, A. Elkahloun, D. Cao, C. Shen, M. Wunderlich, Y. Wang, M.B. Neilly, J. Jin, M. Wei, J. Lu, P.J. Valk, R. Delwel, B. Lowenberg, M.M. Le Beau, J. Vardiman, J.C. Mulloy, N.J. Zeleznik-Le, P.P. Liu, J. Zhang, J. Chen, miR-196b directly targets both HOXA9/MEIS1 oncogenes and FAS tumour suppressor in MLL-rearranged leukaemia, Nat. Commun. 3 (2012) 688.

27. E. Till, C.M. Croce, J.J. Michaille, miR-155: on the crosstalk between inflammation and cancer, Int. Rev. Immunol. 28 (2009) 264-284.

28. J. Zhang, J. Ye, D. Ma, N. Liu, H. Wu, S. Yu, X. Sun, W. Tse, C. Ji, Cross-talk between leukemic and endothelial cells promotes angiogenesis by VEGF activation of the Notch/Dll4 pathway, Carcinogenesis 34 (2013) 667-77.

29. K.R. Kampen, A. ter Elst, E.S.J.M. de Bont, Vascular endothelial growth factor signaling in acute myeloid leukemia, Cell. Mol. Life Sci. 70 (2012) 1307-1317.

30. S. Dias, M. Choy, K. Alitalo, S. Rafii, Vascular endothelial growth factor (VEGF)-C signaling through FLT-4 (VEGFR-3) mediates leukemic cell proliferation, survival, and resistance to chemotherapy, Blood 99 (2002) 2179-2184.

31. S.W. Huang, J.C. Lien, S.C. Kuo, T.F. Huang, PPemd26, an anthraquinone derivative, suppresses angiogenesis via inhibiting VEGFR2 signalling, Brit. J. Pharmacol. 171 (2014) 5728-5742.

32. H.J. Kwak, M.J. Park, C.M. Park, S.I. Moon, D.H. Yoo, H.C. Lee, S.H. Lee, M.S. Kim, H.W. Lee, W.S. Shin, I.C. Park, C.H. Rhee, S.I. Hong, Emodin inhibits vascular endothelial growth factor-Ainduced angiogenesis by blocking receptor-2 (KDR/Flk-1) phosphorylation, Int. J. Cancer 118 (2006) 2711-2720.

33. Y.J. Chen, L.S. Chang, Gallic acid downregulates matrix metalloproteinase-2 (MMP-2) and MMP-9 in human leukemia cells with expressed Bcr/Abl, Mol. Nutr. Food Res. 56 (2012) 1398-1412.

34. J. Wellbrock, W. Fiedler, Clinical experience with antiangiogenic therapy in leukemia, Curr. Cancer Drug Targets, 11 (2011) 1053-1068.

35. C. Li, S.M. Hashimi, D.A. Good, et al. Apoptosis and microRNA aberrations in cancer, Clin. Exp. Pharmacol. Physiol. 39 (2012) 739-746.

36. J.-Q. Du, J. Wu, H.-J. Zhang, et al. Isoquinoline-1,3,4-trione derivatives inactivate caspase-3 by generation of reactive oxygen species, J. Biol. Chem. 283 (2008) 30205-30215.

37. O. Trott, A.J. Olson, AutoDock Vina: improving the speed and accuracy of docking with a new scoring function, efficient optimization and multithreading, J. Comput. Chem. 31 (2010) 455-461.

38. P. Tosco, T. Balle, Open3DQSAR: a new open-source software aimed at high-throughput chemometric analysis of molecular interaction fields, J. Mol. Mod. 17 (2011) 201-208.

39. N.H. Zamakshshari, G.C.L. Ee, S.H. Mah, Z. Ibrahim, S.S. Teh, S. Daud, Cytotoxic activities of anthraquinones from Morinda citrifolia towards SNU-1 and LS-174T and K562 cell lines, Arch. Nat. Med. Chem. 2017. http://dx.doi.org/10.29011/ANMC-110.000010 (epub ahead of print, ANMC-110). 